\title{
El eterno retorno de la mujer fatal en 'Circe' de Julio Cortázar
}

\author{
EUGENIA HOUVENAGHEL \\ AAGEJE MONBALLIEU
}

University of Ghent

\section{Resumen}

Estudiamos la protagonista del cuento 'Circe' a la luz de la rica tradición del arquetipo de la femme fatale. Analizamos, primero, el personaje Delia Mañara, que se construye a partir de fuentes variadas - artísticas e históricas, antiguas y modernas, bíblicas y paganas, europeas y americanas - sobre la mujer mortífera legendaria. Argüiremos, después, que Cortázar inscribe dicho personaje complejo y contradictorio en la visión circular del tiempo de Heráclito. La mujer fatal creada por Cortázar, de acuerdo con la teoría heraclitiana del Eterno Retorno, vuelve a aparecer en todas las épocas, siendo a la vez idéntica y diferente, a la vez Circe, Eva, Diana, the Siren, the spider woman y ... Delia Mañara. Bajo esta perspectiva, proponemos una lectura heraclitiana del cuento: su protagonista simboliza el Eterno Retorno de la femme fatale y encarna la unidad de lo múltiple.

\footnotetext{
Abstract

We study the female protagonist of the tale 'Circe' within the rich tradition of the archetypical femme fatale. We first analyse the character Delia Mañara, constructed on the basis of various sources - artistic and historical, ancient and modern, biblical and pagan, European and American - about the legendary femme fatale. Second, we argue that this complex and contradictory character can be comprehended within the circular time vision of Heraclitus. Cortázar created this fatal woman in line with the theory of the Eternal Return. She appears in all epochs and is both identical to and different from Circe, Eve, Diana, the Siren, the Spider Woman and ... Delia Mañara. From this perspective, we propose a Heraclitian reading of the tale: the protagonist symbolizes the Eternal Return of the femme fatale and has been constructed as the incarnation of unity within multiplicity.
} 


\section{Introducción}

El título del cuento 'Circe' (Bestiario, 1951) de Julio Cortázar refiere a la Circe de la Odisea, mientras que el epígrafe evoca a the Siren, ${ }^{1}$ mujer funesta que forma la simbiosis de las sirenas de la Odisea, la Eva del Génesis y la diosa Diana de la mitología clásica. Evocando en la antesala del cuento a varias mujeres mortíferas, Cortázar anuncia con insistencia que su cuento, protagonizado por Delia, se inscribe en la tradición rica y variada de la femme fatale.

Partiendo del punto de vista que la función principal del paratexto es orientar la lectura en una determinada dirección, nos proponemos seguir y explorar la pista de lectura anticipada en el paratexto. Concretamente, después de haber presentado el arquetipo de la mujer mortífera, comentaremos sucesivamente las características de Circe y the Siren, las mujeres evocadas en el paratexto. Esta exploración paratextual nos llevará al análisis de Delia Mañara, la protagonista del cuento de Cortázar, y al cotejo con las dos mujeres arquetípicas evocadas en el paratexto. Después seguiremos explorando el personaje Delia dentro del marco de la tradición de la mujer fatal, intentando reconocer en sus rasgos la impronta de mujeres mortíferas legendarias.

Por último, nos haremos algunas preguntas centradas en el significado que la tradición de la mujer fatal adquiere en el cuento de Cortázar: ¿Cuál es la función de la tradición del arquetipo en 'Circe'? ¿Qué lugar ocupa el personaje Delia Mañara dentro del marco de dicha tradición? y, finalmente, ¿Qué imagen construye Cortázar sobre la tradición de la mujer mortífera a través de este cuento?

\section{El arquetipo de la mujer fatal}

El arquetipo de la mujer fatal existe en, prácticamente, todas las culturas (Wallace 1960: 236). Los orígenes del arquetipo de la femme fatale se remontan a la mitología de la antigüedad. ${ }^{2}$ Posteriormente, el tipo de la mujer mortífera está omnipresente en el folclore popular y el arte de la cultura occidental. El arquetipo resurge en el romanticismo y florece particularmente en el arte de fines del siglo XIX e inicios del siglo XX. ${ }^{3}$

¿Qué contenido vehicula este arquetipo tan presente en la cultura tanto antigua

1 Personaje femenino de The Orchard Pit por Rossetti, pintor y poeta inglés (1828-1882) quien trabaja el tema de Lilith - o la mujer fatal - también en otras obras literarias (por ejemplo: A Sea Spell 1868) y en sus pinturas (por ejemplo: Lady Lilith, 1863: 64, 68).

2 Los mitos y creencias acerca de las mujeres mortíferas se vienen desarrollando desde la antigüiedad. Los ejemplos más antiguos de la mitología y la religión van desde la diosa sumeria Ishtar, hasta la tradición judía con Lilith (la primera esposa demoníaca de Adán) y la bíblica Dalila. En la tradición mitológica de los clásicos, tenemos a Helena de Troya, Medea y Pandora.

3 En el siglo XIX, tenemos varias representaciones literarias del arquetipo de la mujer fatal: La belle Dame sans Merci (John Keats, 1819), Lorelei (personaje del folclore alemán, utilizado por H. Heine en 1823) y Carmen (de Mérimée 1845). Pensemos también en las presencias de la mujer mortífera en las obras de Oscar Wilde, Edvard Munch y Gustav Klimmt, entre otros. 
como moderna? Durand (1969: 113 y ss.), al analizar la construcción de la mujer mortífera, destaca su carácter contradictorio: la femme fatale combina su dulzor entre cuyos símbolos se cuentan la belleza física, la voz y el arte culinario - con una crueldad innata y una gran depravación que conducen intencionadamente a la muerte de sus víctimas. La combinación de dichas características opuestas está muy presente en la representación simbólica de la femme fatale. El cabello, por ejemplo, el símbolo más fuerte y recurrente de la mágica seducción femenina, representa al mismo tiempo la muerte. Así mismo, el hilo, muy presente en las lindas labores de la mujer mortífera, que se suele aplicar a las tareas de bordar o tejer, es una referencia simbólica a la muerte.

El arquetipo que acabamos de describir guarda cierto parecido con el modelo de la bruja. Sin embargo, la femme fatale se distingue de su 'hermana mayor' en lo que se relaciona con lo sobrenatural, que, estando siempre explícitamente presente en el caso de la bruja, no necesariamente aparece en el caso de la mujer mortífera (Wallace 1960: 4). Ahora bien, aunque hay mujeres fatales que disponen (o parecen disponer) de auténticos poderes sobrenaturales, para la mayoría de ellas, la fuerza proviene meramente de la dulzura de su feminidad. Parecen, decimos, porque la dimensión sobrenatural de la mujer fatal se relaciona más con la instancia narradora de las historias - que suele ser masculina, y, por lo tanto, influenciada por el miedo ante el peligro femenino - que con el auténtico carácter mágico de los poderes de la femme fatale.

Efectivamente, si bien es cierto que en las historias sobre la mujer mortífera, los hombres víctimas son personajes pasivos, quienes, por lo general, ${ }^{4}$ se limitan a sufrir las consecuencias de la belleza y atracción de la mujer mortífera, no podemos caer en la trampa de subestimar la importancia del papel de los hombres en dichos relatos. El propio arquetipo de la mujer fatal es una creación masculina y la perspectiva que se adopta en dichas historias sobre la femme fatale también suele ser masculina. El miedo del hombre por los poderes de la mujer parece constituir el núcleo subconsciente de la tradición de la mujer fatal: se trata en efecto de un mito eterno que interpreta a la mujer como amenaza al dominio del varón sobre el mundo.

\section{Las mujeres mortíferas del paratexto}

\subsection{Circe}

El dulzor femenino de Circe, una de las femme fatales de la Odisea, proviene de la belleza física, la voz, las labores y el arte culinario. Veamos de más de cerca en qué consiste la mágica atracción femenina de Circe. Se trata de una diosa muy bella - caracterizada por el epíteto 'de lindas trenzas' (X: 220); de una cantante - se dice que los hombres 'escucharon a Circe que cantaba con una hermosa voz en su morada' (X: 221); de una mujer que hace labores brillantes - Circe 'se 
aplica a su enorme e inmortal telar' (X: 222); y de una cocinera de platos ricos y dulces - Circe 'mezcló queso, harina y rubia miel con vino de Pramnio' (X: 234-36).

Como suele ocurrir en el caso de la mujer mortífera, la dulzura y belleza de estos elementos son una máscara que disimula su carácter verdadero, que es maléfico. El narrador de la Odisea advierte al lector de que Circe está 'planeando maldades en su corazón' (X: 317) y le concede otro epíteto significativo: 'la de muchos brebajes' (X: 276). Efectivamente, la anfitriona que invita a Odiseo y los tripulantes les ofrece una comida dulce pero envenenada. Lo dulce de la miel, que se asocia con la felicidad y lo erótico (Lupton 1996: 35) disimula los 'brebajes maléficos' (X: 234-36) añadidos a esta comida. Circe provoca la caída de los hombres de Odiseo: después de haber comido el plato hechizado, se transforman en cerdos.

Lo bestial no sólo aparece por medio de la metamorfosis de las víctimas en animales. También cuando los tripulantes de Odiseo la encuentran a Circe, 'la rodea[n] lobos montaraces y leones' (X: 212). Inesperadamente, los animales salvajes no atacan a los hombres de Odiseo, sino que se comportan como si fueran animales domésticos: '[...] se levantaron y jugueteaban alrededor moviendo sus largas colas. Como cuando un rey sale del banquete y le rodean sus perros moviendo la cola - pues siempre lleva algo que calme sus impulsos - así los lobos de poderosas uñas y los leones rodearon a mis compañeros, moviendo la cola' (X: 214-19).

En el caso de Circe, su fuerza no sólo proviene del encanto de sus cualidades femeninas. Circe posee de verdad poderes sobrenaturales: es una auténtica bruja que dispone de una varita mágica (X: 389) y de brebajes (X: 234-36) para transformar a los hombres en animales (X: 235-38). A pedido de Odiseo, la maga manifiesta otra vez sus poderes sobrenaturales, convirtiendo a los tripulantes nuevamente en hombres:

Circe atravesó el mégaron con su varita en las manos, abrió las puertas de las pocilgas y sacó de allí a los que parecían cerdos de nueve años. Después se colocaron enfrente, y Circe, pasando entre ellos, untaba a cada uno con otro brebaje. Se les cayó la pelambre que había producido el maléfico brebaje que les diera la soberana Circe y se convirtieron de nuevo en hombres aún más jóvenes que antes y más bellos y robustos de aspecto. (X: 388-96)

A pesar de sus poderes mágicos, Circe no consigue envenenar a su víctima principal, Odiseo, porque el héroe también dispone de ayuda mágica y divina, al haber recibido el antídoto moly de Hermes. Cuando Circe se da cuenta de que su veneno no tiene el efecto esperado, invita a Odiseo a la cama (X: 333-35), reemplazando 'la carne digestiva' por 'la carne sexual' (Durand 1969: 129). Ahora que Odiseo no tiene ninguna ayuda mágica de Hermes, sí tiene miedo de la maga: '[...] me invitas a subir a tu aposento y a tu cama para hacerme cobarde y poco hombre cuando esté desnudo. No desearía ascender a tu cama si no aceptaras al menos, diosa, jurarme con gran juramento que no vas a meditar contra mí maldad alguna' (X: 339-44). Circe se lo jura a Odiseo, pero de todos modos 
consigue que él se quede con ella como su amante durante un año entero. Los tripulantes le tienen que recordar a Odiseo su misión inicial y la tierra patria (X: 472-74). Circe le recomienda a Odiseo el descensus ad inferos: si realmente quiere volver a Ítaca, tiene que pasar primero por el Hades, el país de los muertos, donde podría escuchar el aviso de Tiresias, el vidente ciego (X: 489-93).

Concluyendo sobre las relaciones entre Circe y Odiseo, el héroe se puede considerar como el prototipo hombre viril de la antigüedad clásica que - gracias a Hermes - no se deja encantar ni humillar por la pócima venenosa de Circe. El héroe ataca a la hechicera sorprendida (X: 321-23) y consigue la libertad de sus tripulantes (X: 383-96). A pesar de la victoria final del antagonista masculino, su tripulación es dominada, transformada y humillada por la diosa y el propio Odiseo se queda largo tiempo en la isla Eea como su amante.

\subsection{The Siren: Eva, las Sirenas, Diana.}

The Siren es una figura más compleja que la primera femme fatale que acabamos de considerar, porque es un personaje misceláneo que combina los rasgos de tres femmes fatales de la antigua tradición literaria occidental, que son la Eva del Génesis, las sirenas de la Odisea ${ }^{5}$ y la diosa Diana de la mitología clásica. La bella Siren - 'a fair golden-haired woman' (608) - combina concretamente la belleza de la voz de las Sirenas de la Odisea ${ }^{6}$ - '[she] stands and sings' (608) y '[she] sings forever' (608) - y el alimento dulce que tiene su origen en los hechos del Pecado Original en el Génesis protagonizados por Eva, '[she’s] holding forth a bright red apple' (608).

El dulzor de ambos elementos - la voz y el alimento - enmascara su verdadero carácter venenoso y mortal. El bello canto de the Siren no es inocente del todo, porque ningún hombre puede resistir su atracción. Cuando el protagonista en su sueño final oye su canto - 'Ven al Amor; Ven a la Vida; Ven a la Muerte' ya no puede ofrecer resistencia: 'But long before I reached her, she knew that all

5 Más en concreto, en el texto de Rossetti se mezclan los motivos bíblicos de la mujer que provoca la caída del hombre por medio de una manzana y de la serpiente, que representa el demonio quien tienta y engaña a Eva con tres elementos de la Odisea, que son el nombre propio de la Sirena/the Siren, su canto irresistible y la muerte del hombre que la escucha.

6 Homero no nos suministra detalles sobre cómo las sirenas matan a los hombres que escuchan su canto. De la descripción misteriosa y lúgubre que sigue podemos concluir que los hombres atraídos por su canto no regresan y mueren de una manera u otra:

Primero llegarás a las Sirenas, las que hechizan a todos los hombres que se acercan de ellas. Quien acerca su nave sin saberlo y escucha la voz de las Sirenas ya nunca se verá rodeado de su esposa y tiernos hijos, llenos de alegría porque ha vuelto a casa; antes bien, lo hechizan éstas con su sonoro canto sentadas en un prado donde las rodea un gran montón de huesos humanos putrefactos, cubiertos de piel seca. (Odisea XII: 39-46)

Aguirre Castro, preguntándose cómo mueren aquellos infelices y qué significa la presencia extraña de la piel seca en la descripción propone lo siguiente: 'Se podría pensar que el hombre atraído por ellas cae en su poder, vivo aún y éstas le dejan consumirse en su prado florido, pues ésa sería la única manera de entender el hecho de que sus huesos aún conserven restos de piel y no que le devoren [...].' (Aguirre Castro 1994: 308) 
her will was mine.' (609). El dulzor del canto the Siren disimula el carácter mortal de la atracción: '[...] and Death's name in her mouth was the very swoon of all sweetest things that be' (609).

También la atracción de la manzana enmascara la esencia peligrosa que provoca la caída del hombre: 'But while I bit it, my brain whirled and my foot stumbled; and I felt my crashing fall through the tangled boughs beneath her feet [...].' (609). La descripción que acabamos de citar es una clara reminiscencia de la caída de Adán, que se interpreta como la caída de la muerte y no la del conocimiento (Durand 1969: 125). Además, Rossetti asocia la manzana con la boca y el beso de la femme fatale, o sea que establece una relación entre 'la carne digestiva' y 'la carne sexual'. Cuando la novia del narrador le da una manzana y le dice, riéndose, que es la fruta de the Siren, él ríe y la come: '[...] and at the heart of the apple was a red stain like a woman's mouth; and as I bit it I could feel a kiss upon my lips.' (608) Este beso ya anuncia el beso mortífero de the Siren al final de The Orchard Pit.

A diferencia de Circe, a la protagonista maléfica de Rossetti no se le atribuyen fuerzas mágicas concretas. Las relaciones de the Siren con la brujería y con la muerte no se basan en hechos o testimonios concretos, sino en un miedo irracional, que se basa en rumores vagos, presentimientos e historias inverificadas. El narrador anónimo de The Orchard Pit dice que la gente tiene miedo y evita el contacto con ella, porque circulan muchas historias sobre su brujería funesta: '[I] heard many tales of those who have died there by the Siren's spell' (608). El narrador de Rossetti recuerda que, de niño, no le era permitido ir al valle de the Siren: '[...] I was taught to shun the place' (608). El narrador de Rossetti no suministra detalles sobre cómo the Siren mata a los hombres, pero sí declara de modo misterioso que ella causa la desaparición definitiva del hombre que se aproxima a ella: 'No man sees the woman but once, and then no other is near; and no one sees that man again'(608).

El valle en el que mueren los hombres se puede interpretar como una referencia al prado en el que están sentadas las sirenas homéricas y donde las rodean huesos humanos putrefactos (Odisea XII: 39-46). También puede leerse como una reminiscencia del valle de Gargafia (Ovidio, Metamorfosis III: 156), consagrado a la diosa Diana. Diana, la diosa de la caza, no se deja seducir por ninguno de sus pretendientes. Tiene un carácter salvaje y provoca sin escrúpulos la muerte de Acteón, quien está descansando con sus compañeros en el valle de Gargafia. Diana se indigna contra el cazador que penetra en su terreno sagrado y le convierte en un ciervo, que está muriendo, destrozado por sus propios perros de caza que le hacen pedazos y devoran sus carnes.

El narrador anónimo presiente que también va a morir en este valle, por ser el siguiente 'novio' de the Siren. Dos veces expresa el presentimiento de su muerte: 'I pass there often now, and look at it as one might look at a place chosen for one's grave. I see nothing, but I know that it means death for me.' (608) y 'Last night, at last, I dreamed how the end will come, and now I know it is near' (609). El narrador no presenció ni experimentó nada extraño pero debido a su imagina- 
ción y el miedo del narrador, en combinación con la fuerza de los rumores que circulan, los poderes de la mujer misteriosa adquieren un carácter mágico.

Aparte de los procedimientos que acabamos de enumerar, el recurso central de la historia de Rosetti que permite que se describan cosas sobrenaturales como si fueran vividas realmente, es el sueño, que sirve de marco a esta historia onírica. El protagonista anónimo, que también es el narrador del relato, cuenta que siempre tiene el mismo sueño de un valle de manzanos. En el manzano más grande está una mujer rubia y bonita, the Siren, que canta y que tiene una manzana en la mano. Debajo del árbol hay un pozo lleno de hombres muertos, que tienen cada uno una manzana mordida en la mano. En el sueño, el protagonista ve que "the pit is full of the bodies of men. They lie in heaps beneath the screen of boughs, with her apples bitten in their hands; and some are no more than ancient bones now, and some seem dead but yesterday' (608). Una noche, sueña cómo va a morir precisamente: dando un paseo con su novia en el valle, oye la voz de the Siren y ve una mano que le ofrece una manzana. Aunque su novia se lo impide, él sigue bajando al manzano de la Sirena quien canta 'Ven al Amor; ven a la Vida; ven a la Muerte' y le ofrece la manzana. Él la acepta y the Siren le da un beso. Cuando el hombre toma un bocado de la manzana, se cae en el pozo y ve las caras blancas de los muertos. En este momento se despierta, con muchísimo miedo, proyectando el sueño en la vida real e interpretándolo como un presagio de su muerte inminente, causada por la mujer mortífera. El narrador es pues una víctima indefensa muerta de miedo, un miedo irracional e inspirado por elementos inverificados y oníricos.

\section{Delia Mañara}

\subsection{Delia y Circe}

En cuanto a la construcción del personaje, Delia tiene mucho en común con Circe, la maga evocada en el título. Efectivamente, Delia - bella y rubia - aplica básicamente el mismo modo operativo que la diosa homérica: la del arte culinario en el cual la dulzura seduce y al mismo tiempo trae consigo el peligro. A Delia le gusta experimentar recetas: prepara bombones y licores sospechosos. Incluso los propios padres de Delia desconfían de los experimentos culinarios de su hija. El parecido con los brebajes mágicos preparados por Circe se refuerza cuando Delia describe de manera misteriosa y extensa la elaboración de sus bombones (69). Lo dulce de los bombones recuerda también la dulzura de la miel de las preparaciones de Circe.

Los sucesivos novios de Delia - Rolo, Héctor y Mario - tienen que probar los productos preparados por la mujer. Las escenas en las que Delia le deja probar los bombones al último de sus novios, que se llama Mario, tienen el matiz de una ceremonia ritual que se celebra en las horas nocturnas $(71,72):^{7}$ 'cuando venía

7 A nuestro modo de ver, es muy adecuado el título Ritos del volúmen de cuentos al que pertenece ‘Circe’. D. Mimoso-Ruiz (1978: 63) ya señaló el carácter ritual del cuento. Véanse el fragmento siguiente: 
la hora de las pruebas, siempre en la sala y casi de noche, y había que cerrar los ojos y definir - con cuantas vacilaciones a veces por la sutilidad de la materia - el sabor de un trocito de pulpa nueva, pequeño milagro en el plato de alpaca' (72).

Igual que los platos de Circe, también los bombones aparentemente deliciosos disimulan un elemento maléfico que se relaciona con lo bestial. ${ }^{8} \mathrm{Si}$ los tripulantes de Odiseo se convierten en cerdos, leones y lobos después de haber comido el plato preparado por Circe, los bombones de Delia contienen trocitos crocantes que en realidad son cucarachas muertas (78-79). La cucaracha, ${ }^{9}$ aparte de ser una reminiscencia de la metamorfosis del hombre creado por Kafka, funciona como símbolo de lo asqueroso ${ }^{10}$ y de la intención maléfica de la mujer de dominarle completamente a Mario. ${ }^{11}$ Tanto Circe como Delia confrontan a sus víctimas masculinas con animales que simbolizan la humillación - cerdos o cucarachas. En cuanto a los leones y los lobos de Circe, comprobamos que Delia tiene una relación estrecha con los gatos y con los perros. El perro que obedece a Delia ${ }^{12}$ puede interpretarse como un novio metamorfoseado, quizás Rolo, cuyo nombre viene de Rodolfo y significa etimológicamente lobo (glorioso).

Si acabamos de explicar que Delia se parece mucho a Circe, también la reacción de Mario ante el peligro femenino tiene más en común con el héroe Odiseo que con la víctima débil e indefensa de the Siren. La relación de éste con Delia

Había que cerrar los ojos para adivinar el sabor, y Mario obediente cerró los ojos y adivinó un sabor a mandarina, levísimo, viniendo desde lo más hondo del chocolate. Sus dientes desmenuzaban trocitos crocantes, no alcanzó a sentir su sabor y era sólo la sensación agradable de encontrar un apoyo entre esa pulpa dulce y esquiva. Delia estaba contenta del resultado, dijo a Mario que su descripción del sabor se acercaba a lo que había esperado (71).

8 No es, pues, inocente que el cuento forme parte del libro Bestiario (1951), puesto que el hombre se asocia con la cucaracha. (Más tarde, cuando se editaron los cuentos completos de Cortázar, 'Circe' se insertó en Ritos, el primer volumen de los relatos.)

9 El propio Cortázar padecía la fobia de encontrar bichos en la comida y tenía que mirar cada bocado antes de comer. Véanse las entrevistas por parte de E. González Bermejo (1979: 31-32) y de O. Prego (1985: 182-83).

10 Ver el ejemplo que da D. Lupton de lo asqueroso de la cucaracha en la comida: 'Should that individual go even further in transgression, such as adding a few dead cockroaches to the meal, those observing may even find their disgust turning to nausea' (Lupton 1996: 29).

11 D. Lupton lo llama ‘an act of humiliation and contamination' (Lupton 1996: 34). ¿Quizás es ésta la razón por la que sus novios anteriores se suicidaron: no simplemente el hecho humillante de haber comido una cucaracha los desesperaba, sino que se daban cuenta de que se iban a casar con un monstruo atractivo?

12 Un gato seguía a Delia, todos los animales se mostraban siempre sometidos a Delia, no se sabía si era cariño o dominación, le andaban cerca sin que ella los mirara. Mario notó una vez que un perro se apartaba cuando Delia iba a acariciarlo. Ella lo llamó (era en el Once, de tarde) y el perro vino manso, tal vez contento, hasta sus dedos (65-66).

La presencia del perro aquí no es gratuita: es una referencia intertextual al décimo canto de la Odisea de Homero. Efectivamente, los hombres metamorfoseados por Circe en leones y lobos, se comparan con perros domésticos: 'Como cuando un rey sale del banquete y le rodean sus perros moviendo la cola - pues siempre lleva algo que calme sus impulsos así los lobos de poderosas uñas y los leones rodearon a mis compañeros, moviendo la cola' (X: 217-19). 
no es estable sino que evoluciona del enamoramiento a distancia al noviazgo oficial. En el cuento de Cortázar, Mario, al igual que Odiseo, lucha ${ }^{13}$ contra las técnicas seductoras de la femme fatale y ambos héroes se resisten a caer en sus redes. Mario, aunque no dispone de la ayuda divina de Hermes, sospecha que el bombón contiene algo malo y no lo come (78-79). Su reacción violenta recuerda el carácter viril de los héroes clásicos tales como Odiseo: furioso, Mario intenta estrangular a su novia, pero Delia sale con vida. Héctor, por su propio nombre, contiene otra reminiscencia al mundo masculino de los héroes: se trata del mejor guerrero troyano. ${ }^{14}$

\subsection{Delia $y$ the Siren}

Con eso, pasemos ahora a las reminiscencias de la Sirena en el cuento de Cortázar. Igual que the Siren, Delia es una mujer aislada: no es popular entre la gente (65), se la suele evitar, la gente le tiene miedo y esta mala fama se basa en las historias y los rumores que circulan. Se murmura, como en the Siren, que ha matado a sus dos novios (64). Rolo y Héctor murieron efectivamente en circunstancias dudosas y sospechosas: Rolo murió de un síncope y Héctor se suicidó. Hasta sus propios padres desconfían de ella, puesto que no les gusta probar los experimentos gastronómicos de su hija. Entre las reminiscencias de the Siren en el alimento ofrecido por Delia, podemos contar el hecho de que se asocia el beso que le da Delia a Mario en la mejilla con el sabor del bombón a la menta (71), igual que se contiene un beso en la manzana de the Siren.

En el relato de the Siren, igual que en el cuento sobre Delia, Los rumores contribuyen al carácter mágico de Delia, quien no es una auténtica maga ${ }^{15}$ que dispone de poderes sobrenaturales. Sin embargo, a través de los ojos del narrador, algunas acciones de Delia adquieren un carácter casi mágico. Leemos, por ejemplo, que Delia es 'demasiado lenta en sus gestos' (65), ${ }^{16}$ o que 'algo le decía a Mario que Delia iba a conseguir cosas maravillosas con los bombones' (71) o que '[Delia] hizo un gesto como para abrir una puertecita en el aire, un ademán casi mágico’ (74). Vemos pues cómo el poder sugerente de los rumores que circulan entre la gente y el de las descripciones subjetivas e influenciadas por el miedo del narrador

13 En este sentido, Mario recuerda al personaje Marius, (Les misérables, Victor Hugo, 1862), un joven idealista quien va a las barricadas del socialismo para luchar por los derechos de los pobres. Es interesante notar que Marius se enamora de Cosette, representación del ángel romántico eterno, que se puede considerar como el polo opuesto de la mujer fatal.

14 La esposa de Héctor, Andromaca, es el modelo de madre amantísima y esposa fiel y el polo opuesto de la mujer fatal.

15 Recuérdese que la Maga también es el nombre de un personaje importante de Rayuela (1963).

16 Véase la interpretación de O. Prego: 'En ese cuento hay además una frase dicha al pasar que, sin embargo, transmite una carga sombría, siniestra, del personaje, de Delia. Es cuando se dice que era 'fina, rubia, demasiado lenta en sus gestos (yo tenía doce años, el tiempo y las cosas son lentas entonces)'. Esa referencia a la lentitud de sus gestos le da al lector la impresión de un ser que está casi fuera del tiempo, de que esta Circe de barrio es un personaje maléfico. (1985: 185). 
reemplazan el verdadero carácter mágico de la mujer y sus acciones que caracterizaba el mito de Circe.

Otro parecido con the Siren se relaciona con la omnipresencia de la muerte. Igual que en el valle de the Siren, todo lo que se aproxima a Delia muere: sus dos novios, Rolo y Héctor; ${ }^{17}$ el conejo, regalado por Héctor; el pez, regalado por la madre de Héctor; el gato con las astillas clavadas en los ojos. Además, el narrador dice que 'De Delia quedab[a] [...] el aura de su respiración a medias en la muerte' (72). Como en el caso de the Siren, la muerte de dichos hombres y animales es misteriosa: no se explica pero sí se relaciona con la influencia maléfica de la mujer.

\subsection{Delia, Diana y spider woman}

Concluida nuestra exploración de las semejanzas y las diferencias entre Delia y las mujeres mortíferas del título y del epígrafe, comprobamos que, al construir a la protagonista del cuento, Cortázar sigue echando mano de la tradición rica y variada de la mujer fatal y añade al personaje Delia reminiscencias de tres mujeres legendarias más: una diosa romana, una figura histórica de la antigüedad clásica y la mujer araña del cine norteamericano de los años 40 .

En primer lugar, Delia es otro nombre que recibe la diosa romana de la caza, Diana, por su nacimiento en la isla Delos, ${ }^{18}$ cuyo valle sagrado ya hemos comentado en el apartado sobre the Siren de Rossetti. En segundo lugar, no un personaje literario, sino una figura histórica aumenta el número de mujeres mortíferas incorporados en el cuento. ${ }^{19}$ A Delia, quien vive en el siglo I a.d. Cristo en Roma, se la conoce como la amante cruel de Tibulo, el poeta elegíaco romano. ${ }^{20}$ El primer libro de las Elegías trata dicha relación amorosa de Tibulo con Delia y dedica atención a la actitud cruel de Delia frente a los hombres que seduce: primero Delia rechaza a su marido para estar con Tibulo, después rechaza

17 Sin embargo, Cortázar declara que ambos novios se suicidaron: 'Y el final del cuento, cuando ella fabrica los bombones con cucarachas y los dos novios anteriores se suicidan porque han comido esos bombones y se han dado cuenta y el narrador se salva porque tiene la sospecha, abre el bombón y ve la cucaracha y se escapa, claro’ (Prego 1985: 183).

18 Ver Ovidio, Metamorfosis, VI: 189-92.

19 Es de notar también que el arquetipo de la mujer fatal no es exclusivo del arte, sino que existen personajes históricos que se pueden considerar como mujeres fatales, de modo que el arquetipo de la mujer mortífera cruza la línea entre la ficción y la realidad. Pensemos, por ejemplo, en Clodia/'Lesbia' (95-50 adC), la amante de Catulo, y en Cleopatra (70 adC-30 adC). Erzsébet Báthory, la 'Condesa Sangrienta' (1560-1614), que según la leyenda utilizaba la sangre de sus jóvenes sirvientas para mantenerse joven, aparece en la novela de Cortázar, 62. Modelo para armar (1968). En la modernidad también se señalan mujeres en la vida real que corresponden al arquetipo de la mujer mortífera: la bailarina exótica y espía convicta Mata Hari (1876-1917) o Theda Bara (actriz estadounidense, cuyo pseudónimo es un anagrama de Arab Death, 1885-1955).

20 B. Terramorsi (1986: 165) lo relaciona con Delos, la isla griega pero el vínculo con la figura histórica tiene más sentido en el contexto de la tradición de la mujer fatal. Como señala J.L. Arcaz Pozo en su edición de Tibulo, etimológicamente, el nombre 'Delia' sí remonta a Delos (1994: 83). 
también a Tibulo para poder estar con otro amante. En la segunda elegía, en la que Tibulo lamenta ante la puerta de Delia que no lo deje entrar, está presente el topo del paraclausithyron. ${ }^{21}$ Este topo reaparece en el cuento de Cortázar, porque Mario de vez en cuando también se encuentra delante de la puerta cerrada de Delia Mañara: 'Entonces Mario se acercaba a la ventana de Delia y le tiraba una piedrita. A veces ella salía, a veces la escuchaba reírse adentro, un poco malvadamente y sin darle esperanzas' (65).

A continuación, otra mujer mortífera es asimilada en el apellido de la protagonista, Mañara. Los críticos han establecido la relación con la araña (Terramorsi 1986: 164), pero no directamente con la versión norteamericana de la mujer mortífera. Efectivamente, si son los franceses los que la denominan femme fatale, los norteamericanos la llaman spider woman (mujer araña) en el cine negro. En los años 40, tras los cambios producidos en la sociedad norteamericana durante la II Guerra Mundial, surgen nuevos personajes femeninos y entre las novedades destaca una mujer hermosa y cruel, que utiliza su belleza y su sexualidad para lograr lo que desea mediante la seducción. ${ }^{22}$

Dentro del contexto de the spider woman, conviene recalcar que Delia se asocia repetidamente con la araña, animal negativo que simboliza la feminidad fatal (Durand 1969: 115). Su madre dice, por ejemplo, que Delia 'había jugado con arañas cuando chiquita' (66). Durand (115) describe el método operativo del animal como sigue: 'escondido en la oscuridad, ${ }^{23}$ feroz, ágil y atando sus presas por medio de un hilo mortal'. ${ }^{24}$ El arma principal de la araña - y de la mujer fatal - es el hilo (Durand 1969: 118). La protagonista de Cortázar trabaja con hilos y tejidos, y le muestra a Mario los proyectos de costura y bordado $(68,77)$ que le ocupan.

21 El topo de paraclausithyron se describe cómo sigue: 'A lover's song at his beloved's door, in which he begs for admision and laments his exclusion. It occurs in a variety of poetic genres (e.g. lyric, epigram, comedy, mime, elegy)' (Hornblower; Spawforth 1996: 1112).

22 Entre las películas sobre fatales memorables del cine negro norteamericano, podemos citar: Perdición (Double Indemnity, Billy Wilder, 1944, actriz Barbara Stanwyck); Forajidos (The Killers, Robert Siodmak, 1946, actriz Ava Gardner); El cartero siempre llama dos veces (The Postman always rings twice, Tay Garnett, 1946, actriz Lana Turner), La dama de Shanghai (The Lady from Shangai, 1948, Orson Welles, actriz Rita Hayworth).

23 El narrador asocia a Delia con otro animal que se vincula directamente con el ámbito nocturno: las mariposas (66). En una entrevista con O. Prego, Cortázar explica el carácter morboso de las mariposas:

OP: El episodio de las mariposas me hizo pensar en Mauricio Babilonia [personaje de Cien años de soledad de G. García Márquez], cuya presencia es anunciada siempre por la aparición de mariposas amarillas.

JC: Pero yo creo que debo haber pensado por mi parte (porque las mariposas de Mauricio Babilionia son diurnas) en el lado nocturno. Vos sabés que las mariposas están profundamente asociadas con la muerte. (1985: 184).

24 Además, según L. Juárez, el apellido Mañara también puede establecer el vínculo entre Delia y el mito de Don Juan, porque '[...] algunas versiones que retoman el mito, llaman al personaje [de Don Juan] Mañara’ (2002: 27). Delia sería una variante femenina de Don Juan porque ambos personajes se burlan de sus víctimas - ver 'Delia se sonreía como burlándose' (69) - y porque en las dos historias está presente una ‘cena macabra’ (Juárez 2002: 27). 
Entre los aspectos de las películas del cine negro que se mantienen en el relato de Cortázar, conviene citar el ambiente ciudadano. Es de notar que ni el jardín de Eva, ni el monte y el bosque en el que se cazan animales salvajes de Diana, ni el ambiente paradisíaco de la isla ${ }^{25}$ de Circe y del mar que la rodea se mantienen en el cuento de Cortázar. Con los elementos de la naturaleza de las historias tradicionales, contrastan una serie de componentes relacionados con la ciudad de Buenos Aires - muy presente en el cuento - que pertenecen a un ambiente muy alejado de las escenas en plena naturaleza en las que se mueven las mujeres fatales evocadas en el paratexto. Se trata aquí, igual que en el cine negro, de una mujer fatal urbana, que se mueve en las calles de una gran ciudad. ${ }^{26}$

Otra reminiscencia de las películas del cine negro es la música para piano que está presente en la historia de Delia, quien toca el piano maravillosamente $(71-72,77)$ y cuyas melodías suelen encantarles a los hombres (recordando el arma de seducción de las Sirenas). También en la película Cara de ángel, ${ }^{27}$ las notas musicales surgidas de los dedos de Diane ${ }^{28}$ acompañan los momentos mortales. La melodía de piano que se repite se convierte, en esta película, en una refrán mortal, como si fuera un ritual celebrado por la mujer fatal. La música recuerda el arma de seducción de las Sirenas homéricas y puede interpretarse - en Cara de ángel y en el relato sobre Delia - como la versión actualizada del canto que hipnotiza a los varones.

\section{Conclusiones: el Eterno Retorno de la femme fatale}

Volvamos a los interrogantes formulados en la introducción. ¿Cuál es la función de la tradición del arquetipo de la mujer fatal en 'Circe'? Cortázar recurre a esta tradición para construir el personaje de la mujer fatal y el personaje de la víctima, seleccionando componentes de los relatos y documentos sobre Circe, the Siren, Eva, Diana, Delia y the spider woman. Igual que Rossetti, a quien cita en el epígrafe, Cortázar echa mano de fuentes literarias e históricas y combina los elementos seleccionados. La tradición de la mujer mortífera le sirve pues de materia prima con la que realiza un bricolaje libre. Dicho bricolaje mítico basado en la rica tradición del arquetipo de la mujer fatal translade el relato hacia lo fantástico. Y dicho carácter fantástico de 'Circe’ se anuncia ya explícitamente en el paratexto, por medio de las referencias a varios de estos mitos.

¿Qué lugar ocupa el nuevo personaje así creado, Delia Mañara, dentro del marco de dicha tradición? Delia se puede considerar como una simbiosis: un personaje múltiple. Combinando las tradiciones bíblica y pagana, antigua y moderna, las mitologías nórdica y mediterránea, lo europeo y lo americano, lo fantástico y lo cotidiano, el nivel ficticio y el nivel histórico, Delia de hecho es un personaje

25 La Isla Eea, cerca de la costa Oeste de Italia.

26 Mario, por su parte, no tiene nada que ver con los antihéroes pasivos de las novelas negras y películas de este género que se rinden sin resistencia.

27 Angel Face, 1952, dir.: Otto Preminger.

28 Delia es otro nombre de Diana, la diosa de la caza. Cfr. Nota 29. 
contradictorio que salva más de un abismo aparentemente infranqueable.

La imagen que Cortázar transmite por medio de este cuento parece relacionarse estrechamente con la propia tradición de la mujer fatal en la cual se inscribe el cuento. La mujer fatal se presenta como un elemento que, de acuerdo con la teoría heraclitiana del Eterno Retorno, vuelve a aparecer en todos los tiempos y en todas las tradiciones, siendo a la vez la misma y diferente. Hay varios elementos textuales que refuerzan la idea de la eterna repetición de las historias sobre la femme fatale, que se repite en diferentes mundos.

Así, la mudanza de Delia 'a cuatro cuadras' (65) se presenta como un traslado a otro mundo; los paseos solitarios de Delia del nuevo barrio al antiguo barrio (65) también se pueden leer como referencias a dos mundos distantes que se cruzan. La repetición a lo largo del cuento de determinadas actividades y situaciones - tales como los bombones y licores preparados por Delia, los animales que le rodean, la música cuando Delia toca su piano - contribuye a la creación del carácter circular del tiempo en el cuento. Esta idea de circularidad temporal y del encuentro de mundos distantes se intensifica porque dichos componentes remiten - bajo una forma actualizada pero reconocible - a los mitos antiguos de Circe, Eva y las Sirenas.

Dentro del mismo contexto de la creación de un ambiente de eterna repetición en el cuento, conviene citar la presencia de la luna. ${ }^{29}$ Refiriéndose a Mircea Eliade, Adrián Huici dice que la luna no sólo es imagen de la muerte y de la feminidad, sino que también es 'el símbolo por excelencia del Eterno Retorno' (1991-1992: 416). ${ }^{30}$ En las dos últimas páginas de 'Circe', se menciona a la luna tres veces: 'Algo de luna se acostaba ya en el piso cerca de Delia, en el plato de alpaca que Delia guardaba en la mano como otra pequeña luna' (78) y 'La luna cayó de plano en la masa blanquecina de la cucaracha, [...]' (78). La forma circular de la luna recuerda la descripción de Heráclito ${ }^{31}$ del tiempo, que no es lineal, sino que se debe entender como un círculo: todo suceso del universo ha ocurrido ya un millón de veces; la historia se repite en un eterno retorno. Heráclito defiende la tesis de la unidad armónica de los contrarios: lo uno es lo múltiple. Delia es a la vez Eva, Circe, the Siren, las Sirenas, Diana y la mujer araña o spider woman: es todas las mujeres fatales. Bajo esta perspectiva, aventuramos la hipótesis que Delia ha sido construida para simbolizar todas las Circes del

29 Luna o Febe es también el nombre que en el cielo se le daba a la diosa romana Diana o Delia de la caza.

30 Véanse el fragmento siguiente de Le mythe de l'éternel retour d' Eliade: Basta recordar aquí que, de hecho, la Luna sirve para 'medir' el tiempo [...], si sus fases manifiestan - mucho antes del año solar y de una manera mucho más concreta - una unidad de tiempo (el mes), la luna al mismo tiempo manifiesta el 'eterno retorno'. [...] Esto significa que el ritmo lunar no sólo manifiesta intervalos breves (semana, mes), sino que sirve también de arquetipo para las duraciones más prolongadas; de hecho, el 'nacimiento' de una humanidad, el crecimiento, la decrepitud (su 'usura') y la desaparación están relacionados al ciclo lunar (1969: 105-106).

31 Cortázar está muy familiarizado con la filosofía de Heráclito. Hay reminiscencias al filósofo en varias de sus obras de ficción, tales como Rayuela, 'Sobremesa' (1956, Final del juego) o 'Todos los fuegos el fuego' (1966, Todos los fuegos el fuego). 
universo y del tiempo. Proponemos, por lo tanto, una lectura heraclitiana de la historia de Delia, la cual se debería entender como un relato que encarna el eterno retorno de la mujer mortífera.

\section{Obras citadas}

Aguirre Castro, Mercedes, 1994. 'El tema de la mujer fatal en la Odisea', Cuadernos de Filología Clásica, 4: 301-17.

Alazraki, Jaime, 1983. En busca del unicornio: los cuentos de Julio Cortázar (Madrid: Gredos).

Borges, Jorge Luis, 1986. Discusión, $3^{\mathrm{a}}$ ed. (Buenos Aires/ Madrid: Emecél Alianza).

Cortázar, Julio, 2004. Los relatos, 1. Ritos, 4a ed. (Madrid: Alianza).

Durand, Gilbert, 1969. Les structures anthropologiques de l'imaginaire (Poitiers: Bordas).

González Bermejo, Ernesto, 1979. Conversaciones con Cortázar (México: Hermes).

Homer, 1995. The Odyssey I (With an English translation by A.T. Murray. Revised by George E. Dimock), $2^{\text {a }}$ ed., ed. G. P. Goold (Cambridge, MA/ London: Harvard UP).

Homero, 2005. Odisea, 16a ed., ed. José Luis Calvo (Madrid: Cátedra).

Juárez, Laura, 2002. 'Tradición y ruptura: Apuntes sobre el repertorio mítico en algunos relatos de Julio Cortázar', in Mario Goloboff et al., Julio Cortázar y el relato fantástico (La Plata: Universidad Nacional de la Plata), pp. 15-29.

Lupton, Deborah, 1996. Food, the Body and the Self (London: Sage).

Mimoso-Ruiz, Duarte, 1978. 'Circé de Julio Cortázar’, Revue de Littérature Comparée, 52: 60-73.

Prego, Omar, 1985. La fascinación de las palabras. Conversaciones con Julio Cortázar (Barcelona: Muchnik).

Rossetti, Dante Gabriel, 1911. The works of Dante Gabriel Rossetti, ed. William Michael Rossetti (London: Ellis).

Terramorsi, Bernard, 1986. 'Le discours mythique du fantastique dans les contes de Julio Cortázar', en Coloquio Internacional. Lo lúdico y lo fantástico en la obra de Cortázar, ed. Université de Poitiers, Centre de recherches Latino-Americaines (Madrid: Fundamentos), I: 163-76.

Tibulo, 1994. Elegías, ed. Juan Luis Arcaz Pozo (Madrid: Alianza).

Wallace, Albert Halan, 1960. The fatal woman in French literature of the nineteenth century (Chapel Hill: University of N.C.). 